\title{
STUDY OF POLYPYRROLE FILMS MODIFIED WITH COPPER AND SILVER MICROPARTICLES BY ELECTROCHEMICAL CEMENTATION PROCESS
}

\author{
ÁLVARO A. ARRIETA ALMARIO*A, ROBERTO L. VIEIRA ${ }^{B}$

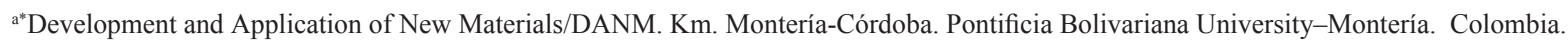 \\ ${ }^{b}$ Dpt. of Chemistry Physic. School of Sciences. University of Minho - Portugal
}

\begin{abstract}
Electroactive polypyrrole (PPy) films obtained under potentiostatic electropolimerization from aqueous solutions of pyrrole doped with sulfate $\left(\mathrm{SO}_{4}^{2-}\right)$ anions were modified by incorporation of copper $(\mathrm{Cu})$ and silver $(\mathrm{Ag})$ microparticles using electrochemical cementation process. The electrochemically deposited and dissolving processes metals $(\mathrm{Cu}$ and $\mathrm{Ag})$ onto and from polypyrrole were investigated. The PPy-Cu and PPy- $\mathrm{Ag}$ electrodes were characterized by electrochemical techniques and scanning electron microscopy (SEM) analysis and the electrochemical response of these modified electrodes was compared to that of the unmodified polypyrrole electrode. The results indicate that two forms of metal, valence and elemental ones, can be formed on polypyrrole at a constant cathodic potential. However, only the valence metal can be left on polypyrrole at the anodic potential. The copper and silver particles interact with polypyrrole films involving a strong complex formation affecting its electrochemical behavior. Scanning electron microscopy measurements show that dendritic-like metal aggregates are formed on the film surface. The electrochemical experiments reveal that metal deposition on conducting polymer can be envisaged as an attractive method for the electrodes fabrication.
\end{abstract}

Keywords: Polypyrrole, Electrochemical cementation, Copper and Silver microparticles.

\section{2. INTRODUCTION}

There have been many advances in the application of conducting polymer and it is certain that this tendency will continue, inevitably encouraging research to find improved properties. Conducting polymers have been investigated for use as the electrode materials for a number of applications, including rechargeable batteries, electrochemical sensors, etc. [1,2]. Among the conjugating conducting polymers, polypyrrole is the most representative one for its easy polymerization and controllable property of switching it between conducting and insulating states by doping and undoping counterions into polymer matrix, as well as its chemical and thermal stabilities. These characteristics make it widely used in microelectronic devices, batteries, and sensors $[3,4]$.

In recent years, several developments in polymer coated electrodes that incorporate metal have been carried out. Composite materials consisting of metal aggregates and conducting polymers attract considerable interest for basic research because of their technological applications in heterogeneous catalysis, environmental science, microelectronics and magnetism. Moreover, it has also been found that the conducting and the sensing behavior of conducting polymers could be further improved by imbedding metal particles into the polymer matrix to form a metal polymer complex [5-7]. The polymer serves as a conducting matrix which supports, separates and stabilizes the metal clusters. Deposition of metal particles onto polymer modified films has been found to be useful in the field of electrocatalysis $[8,9]$ and the electrodes have enhanced the selectivity and the sensibility of many interesting electroanalytical reaction and improved the function of amperometric biosensor and potentiometric sensor $[10,11]$.

The incorporation of metal microparticles into polymer films can be accomplished by electrolysis (applied potential or applied current). Since the cementation process seems to be promising in the polymer modification concept [12-14] because its convenience, good economy, and the wealth of current plating knowledge [15]. In this process, the composite material is synthesized by the oxidation of the respective monomer and further deposition of the metallic species from an aqueous solution of the suited cation. The metal particles usually used for the modification of polypyrrole films are platinum, nickel complexes, rhodium and cobalt complexes [16-19]. Although several researchers had focused their studies on the modification of conductive polymers with metals and the characteristics of the prepared complexes [2022]. Nevertheless, a detailed understanding of the electrodeposition process of metals onto the conductive polymers and the effect of the interaction of metalconducting polymer about the polymer properties has yet to be developed. It is important to know the effects of the modification by incorporation of metals microparticles by cementation process on the electrochemical behaviour of the conducting polymers films.

Hence, in the present work, we study the electrochemical behaviour of PPy modified with copper and silver microparticles by cementation process. The PPy electrodeposition was performed using sulfate anion as doping agent and after that the PPy films was formed in the electrodes surface, this was immersed in aqueous sulfate acid solution containing $\mathrm{Cu}^{2+}$ (for copper incorporation) and $\mathrm{Ag}^{+}$(for silver incorporation) ion where the cementation process occurred. The prepared PPy-metal $(\mathrm{Cu}$ or $\mathrm{Ag})$ electrodes were characterized cyclic voltammetry and scanning electron microscopy. The results are explained in terms of the modification of the electrochemical properties of the polymer films caused by the incorporation of copper and silver microparticles. In this study, the results from scanning electron microscopy and cyclic voltammetry (CV) hinted that the PPy-Ag and PPy-Cu interaction may involve a strong complex formation rather that a simple ion adsorption.

\section{EXPERIMENTAL}

All chemical used were of analytical reagent grade from Aldrich-Sigma and were used without further purification. The solutions were obtained by solving substances in ultra-pure water (Milli-Q Millipore).

The PPy polymerization, the $\mathrm{Cu}$ and $\mathrm{Ag}$ cementation onto PPy, and the dissolution of the elemental $\mathrm{Cu}$ and $\mathrm{Ag}$ experiments were carried out using a three electrode cell at room temperature. The polypyrrole films were deposited on working electrode from platinum disk which was polished with $0.3 \mu \mathrm{m}$ alumina suspension using a microcloth polished pad and risen with deionised water in a ultrasonic bath for $30 \mathrm{~min}$ to remove any residue. The auxiliary electrode used during the polymerization was a platinum gauze, meanwhile when voltammetric experiment were made the auxiliary electrode was a conventional platinum electrode. The potentials were referred to an $\mathrm{Ag} / \mathrm{AgCl}$ electrode in a saturated $\mathrm{KCl}$ aqueous solution. All of the electrochemical measurements were performed at room temperature using a potentiostat/galvanostat (Model 273, EG\&G from Princeton Applied Research) and recorded on a computer.

The polypyrrole were obtained from an electrolytic solution of pyrrole $(0.2$ $\mathrm{M})$ in aqueous media and using as doping agent sulfuric acid / $\mathrm{H}_{2} \mathrm{SO}_{4}(0.1 \mathrm{M})$. The polymer films were grown on Pt disk substrate by applying $0.8 \mathrm{~V}$ (vs. $\mathrm{Ag}$ / $\mathrm{AgCl}$ ) during $300 \mathrm{~s}$. Once prepared, the polymeric electrodes were extracted from the solution and washed thoroughly prior use. The cementation process was performed introducing the $\mathrm{PPy} / \mathrm{SO}_{4}^{2-}$ electrodes in solutions containing $0.1 \mathrm{M}$ of $\mathrm{CuSO}_{4}$ in $0.1 \mathrm{M}$ of $\mathrm{Na}_{2} \mathrm{SO}_{4}$ for the $\mathrm{Cu}$ microparticles deposition and $0.1 \mathrm{M} \mathrm{Ag}_{2} \mathrm{SO}_{4}$ in $0.1 \mathrm{M}$ of $\mathrm{Na}_{2} \mathrm{SO}_{4}$ for the $\mathrm{Ag}$ microparticles deposition. The deposited metal ( $\mathrm{Ag}$ and $\mathrm{Cu}$ ) was electrochemically removed in $0.1 \mathrm{M} \mathrm{H}_{2} \mathrm{SO}_{4}$ until all the elemental metal had been completely dissolved, but the valence metal onto PPy remained. The cyclic voltammetric experiments were carried out in $\mathrm{KCl}(0.1 \mathrm{M})$. The morphology of the films was studied with a scanning electron microscope using a SEM model 8360, Cambridge.

\section{RESULTS AND DISCUSSION}

During the electrodeposition of PPy a reproducible behavior of potentiostatically grown of films was observed. The I-t curves recorded during the polymerization of $\mathrm{PPy} / \mathrm{SO}_{4}{ }^{2-}$ showed the characteristic stepped shape of 
the potentiostatic polymerization of polypyrrole. When the pyrrole is oxidized in the presence of an electrolytic solution (i.e. doping agents) such as sulfate, the anions of the electrolytic solution are incorporated into the structure of the polypyrrole. The film formation is characterized by three distinct stages. The first part of the curve (zone A) consists in the diffusion controlled monomer oxidation, in the second part (zone B) the nucleation phenomenon takes place, and in the third part (zone C) continuous and gradual polymer growth (Figure 1). After of PPy films formation, the metal electrodeposition process was carried out. So, in order to find the metal deposition potential the $\mathrm{PPy} / \mathrm{SO}_{4}{ }^{2-}$ electrodes were immersed in an acidic sulfate solution containing metal ion $\left(\mathrm{Cu}^{2+}\right.$ and $\mathrm{Ag}^{+}$to $\mathrm{PPy}-\mathrm{Cu}$ and $\mathrm{PPy}-\mathrm{Ag}$ respectively) where the cementation process was conduced by cyclic voltammetric experiments.

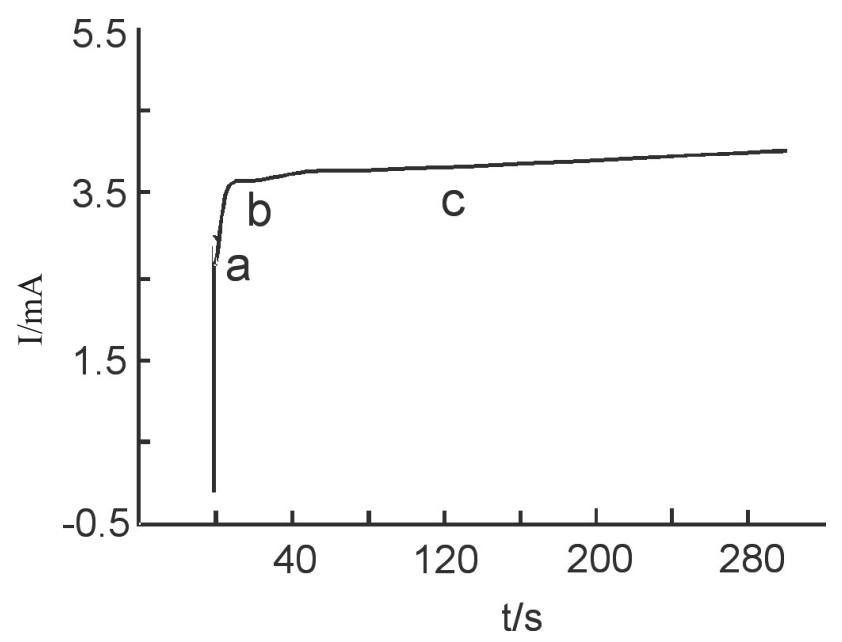

Figure 1: Potentiostatic polymerization curve for the electrodeposition of polypyrrole from aqueous electrolyte; $0.2 \mathrm{M}$ pyrrole, $0.1 \mathrm{M}$ at $0.8 \mathrm{~V}$.

In the Figure 2, is illustrated the voltammetric curves recorded during the electrochemical deposition process of $\mathrm{Cu}$ and $\mathrm{Ag}$ onto $\mathrm{PPy} / \mathrm{SO}_{4}{ }^{2-}$ film in presence of $\mathrm{Cu}^{2+}$ and $\mathrm{Ag}^{+}$ions. As can be seen, the voltammetric response of the copper deposition process onto $\mathrm{PPy} / \mathrm{SO}_{4}$ electrode (figure 2.a), display one cathodic peak at $-0.20 \mathrm{~V}$ and one anodic peak at $0.17 \mathrm{~V}\left(\mathrm{E}_{1 / 2}=-0.01 \mathrm{~V}\right)$ and in the silver deposition process (figure 2.b), the voltametric response consist in an cathodic peak at $0.32 \mathrm{~V}$ and in the reverse scan a anodic peak about $0.46 \mathrm{~V}$ $\left(\mathrm{E}_{1 / 2}=0.39 \mathrm{~V}\right)$. In both cases, copper and silver depositions, the cathodic peaks corresponds to the up-take and reduction of metals ions $\mathrm{Cu}^{2+}$ to $\mathrm{Cu}^{0}$ and $\mathrm{Ag}^{+}$to $\mathrm{Ag}^{0}$ in the $\mathrm{PPy} / \mathrm{SO}_{4}^{2-}$ - films, and the anodic peak correspond to the dissolution of metal $\mathrm{Cu}$ and $\mathrm{Ag}$ aggregates.

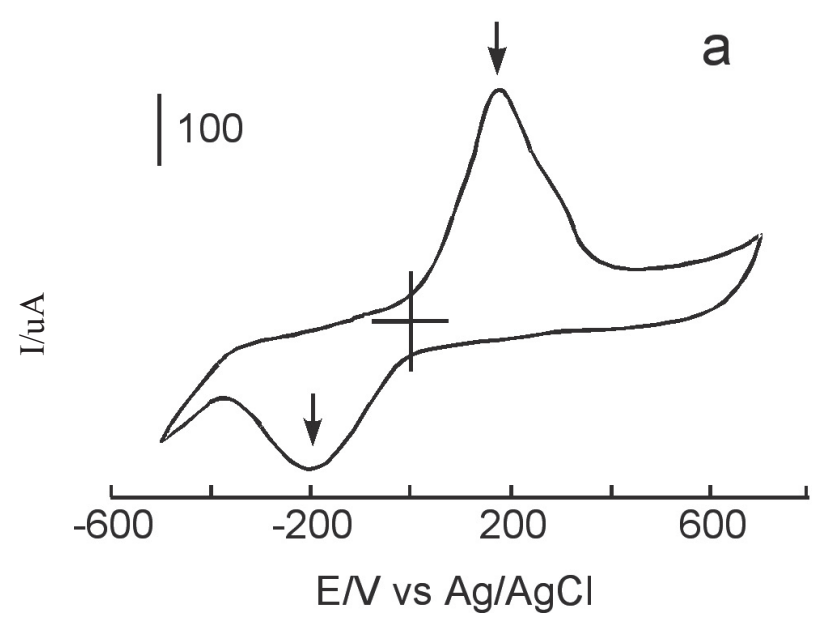

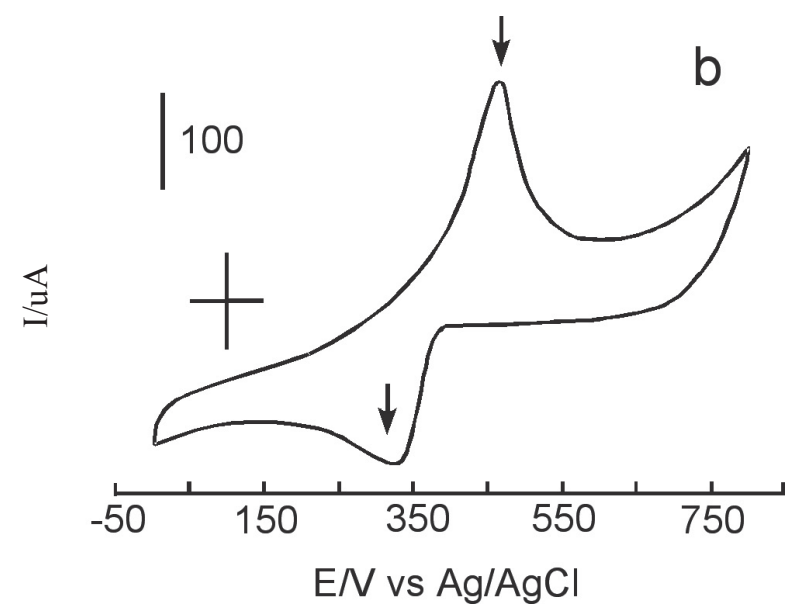

Figure 2: Voltammograms for metal microparticles deposition onto PPy films carried out with scan rate of $500 \mathrm{mV} \mathrm{s}^{-1}$; a) electrochemical cementation of $\mathrm{Cu}$ and b) electrochemical cementation of $\mathrm{Ag}$.

Although the mechanism of the electrochemical cementation process of the metals onto the conducting polymer is not well defined, the phenomena for the deposition of $\mathrm{Cu}$ and $\mathrm{Ag}$ onto PPy observed in our experiments is similar with that of underpotential deposition metal on a metal substrate $[22,23]$. So, the electrochemical depositing and dissolving curves (a) and (b) in Fig 2, it was found that metals particles were significantly deposited onto PPy at a potential more negative than $0.36 \mathrm{~V}$ for silver and $-0.10 \mathrm{~V}$ for copper in the cathodic scan, and the deposited metals can be markedly dissolved at a potential more positive than $0.47 \mathrm{~V}$ for silver and $0.25 \mathrm{~V}$ for copper.

Hence from these cyclic voltammetric experiments, the potential for the deposition of silver and copper is found to be $0.36 \mathrm{~V}$ and $-0.1 \mathrm{~V}$ respectively. These potentials were used for the potentiostatic deposition of metals particles using a ranging of electrochemical charges. In the metal cementation process by chronoamperometric method, two forms of metal, valence and elemental ones can be formed on PPy films at the constant cathodic potential. Then, the elemental $\mathrm{Ag}$ and $\mathrm{Cu}$ of the modified electrodes was dissolving at constant anodic potential of $0.47 \mathrm{~V}$ and $0.25 \mathrm{~V}$ respectively.

The figure 3 represents the chronoamperometric dissolution curves of the Ag metal after depositing $0,5,10,15,25 \mathrm{mC}$ of $\mathrm{Ag}$ onto a PPy films formed with $120 \mathrm{mC}$. It can be observed that the anodic dissolution of deposited $\mathrm{Ag}$ disappears when the charge passed for depositing $\mathrm{Ag}$ is less than $5 \mathrm{mC}$ and this curve is practically same that pure PPy. In similar experiments carried out for $\mathrm{Cu}$ dissolution was found a valor of $9 \mathrm{mC}$. This indicates that a prior deposition of valence $\mathrm{Ag}$ and $\mathrm{Cu}$ onto PPy is formed with a stronger interaction, and this kind of metal deposition cannot be removed in dissolution treatment. So, valence metal is deposited onto PPy and forms a more stable metal-PPy complex than elemental metal does.

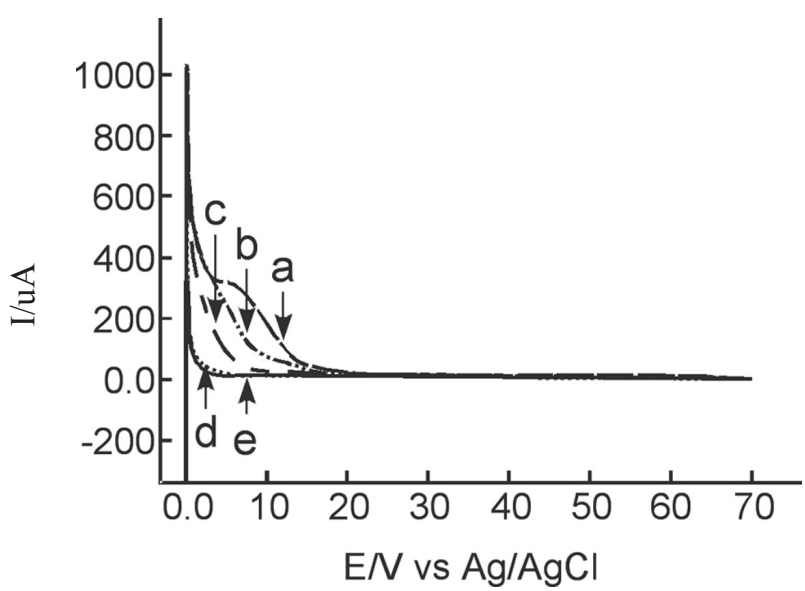

Figure 3: Potentiostatic dissolution at $0.47 \mathrm{~V}$ of $\mathrm{Ag}$ deposited with different charges onto PPy films; a) $25 \mathrm{mC}$, b) $15 \mathrm{mC}$, c) $10 \mathrm{mC}$; d) $5 \mathrm{mC}$, e) unmodified PPy film $(0 \mathrm{mC})$. 
The electrochemical behavior of the metal modified polymer has been examined and compared with the corresponding pristine PPy (figure 4). The behavior of PPy film was observed by recording cyclic voltammograms of the freshly prepared films in $0.1 \mathrm{M} \mathrm{KCl}$ aqueous solution (figure 4.a.) at a scan rate of $0.1 \mathrm{~V} \mathrm{~s}^{-1}$. In agreement with information presented in the literature [24], the PPy electrodes doped with multivalent doping agents such as $\mathrm{SO}_{4}{ }^{2-}$ shows a voltammetric curves with two redox couples. When $\mathrm{PPy} / \mathrm{SO}_{4}{ }^{2-}$ electrode was negatively polarized in the presence of $0.1 \mathrm{M} \mathrm{KCl}$ aqueous solution, it behaves as cation-exchange membrane; that is, the negative charge created in the polymer network is neutralized by the incorporation of cations from the solution. In the second process, occurring at higher voltages, the PPy film gets highly oxidized and anions from the electrolyte are inserted into the film to maintain the charge balance, this electrochemically transformation is generally interpreted by polaron/bipolaron model $[25,26]$.

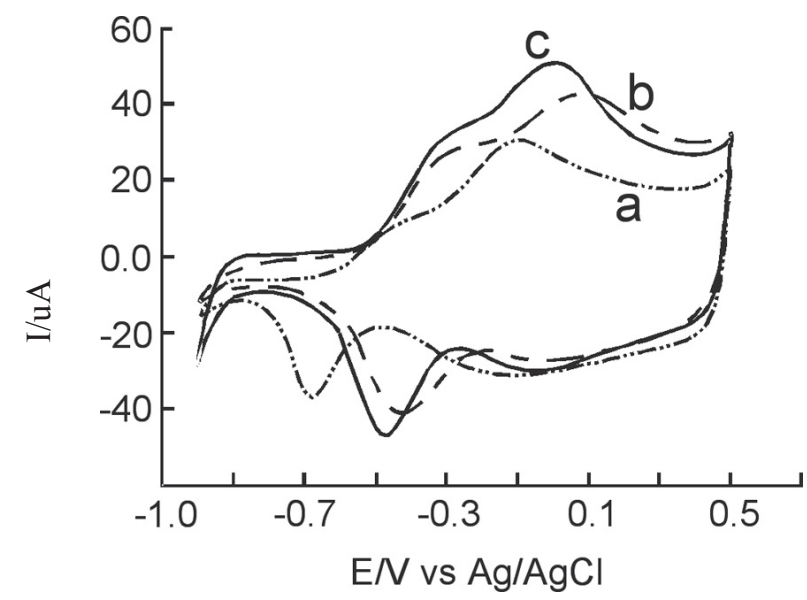

Figure 4: Cyclic voltammetry of a) unmodified PPy film, b) PPy film modified with copper microparticles (PPy-Cu) and c) PPy film modified with silver microparticles (PPy-Ag); recorded at $100 \mathrm{mV} \mathrm{s}^{-1}$ in $\mathrm{KCl} 0.1 \mathrm{M}$

The electrochemical behaviour of the metal microparticles modified PPy electrodes (PPy-Ag and $\mathrm{PPy}-\mathrm{Cu}$ ) in $\mathrm{KCl}$ solution, showed similar trends than the non-modified PPy electrodes (figures 4.b and 4c); so, movements of both anions and cations take place during redox reactions. But, the deposition of metal microparticles leads to a significant increase in the anodic and cathodic current along with a shift of the oxidation and reduction peaks potentials, as clearly shown in the figure 4 . Besides, after of 100 consecutives switching, the reduction of the peak current intensity was higher (about $10 \%$ ) for the non-modified PPy electrodes, while that the metal microparticles modified PPy electrodes the peak current reduction was smaller (about 7\%). So, in general, the best stability was found for PPy-metal (PPy-Ag and PPy-Cu). Therefore, according to these results, it can be concluded that the incorporation of copper and silver microparticles into PPy electrodes significantly improves the stability.

In other hand, it was carried out the conductivity measurements which are listed in the table 1. As can be observed, the metal microparticles deposited onto PPy films notably increase its conductivity. Furthermore, PPy films containing valence metal also presents an excellent conductivity. The conductivity of PPy films measured under similar conditions in which was deposited the metals microparticles (same potential and time used to metal deposition in $0.1 \mathrm{M}$ $\mathrm{H}_{2} \mathrm{SO}_{4}$ without metal ions) was observed a slight diminution in the conductivity, indicating that during metal deposition process onto PPy films at a cathodic potential the undoping phenomena is very small compared with microparticles deposition. Therefore, can be concluded that the valence metal remained onto PPy films can improve the conductivity of PPy electrodes.

Table I. Variation of conductivity of PPy films in several experimental conditions:

\begin{tabular}{|c|c|}
\hline PPy film & Conductivity \\
\hline PPy film (I) & $3.74 \mathrm{~S} \mathrm{~cm}^{-1}$ \\
\hline PPy film (II) & $3.38 \mathrm{~S} \mathrm{~cm}^{-1}$ \\
\hline PPy film (III) & $15.87 \mathrm{~S} \mathrm{~cm}^{-1}$ \\
\hline PPy film (IV) & $13.92 \mathrm{~S} \mathrm{~cm}^{-1}$ \\
\hline
\end{tabular}

I) Unmodified; II) Unmodified and reduced at $0.36 \mathrm{~V}$ in $\mathrm{H}_{2} \mathrm{SO}_{4}$; III) bulk and valence $\mathrm{Ag}$, deposited at $0.36 \mathrm{~V}$ in $\mathrm{Ag}_{2} \mathrm{SO}_{4} / \mathrm{Na}_{2} \mathrm{SO}_{4} ; \mathrm{IV}$ ) valence $\mathrm{Ag}$, After of dissolving the deposited bulk $\mathrm{Ag}$ in $\mathrm{H}_{2} \mathrm{SO}_{4}$.

In order to confirm the presence of $\mathrm{Cu}$ and $\mathrm{Ag}$ particles in the PPy film, scanning electron microscopy analysis was carried out (figure 5). As observed in the Figure 5a, the PPy deposited present a grained texture and must be compared with the much coarser cauliflower structure which is commonly found [27]. In other hand, the figure $5 \mathrm{~b}$ and $5 \mathrm{c}$ shows the SEM photographs of the distribution of the $\mathrm{Cu}$ and $\mathrm{Ag}$ deposited on the surface of PPy, it can be observed a large amount of embedded $\mathrm{Cu}$ and $\mathrm{Ag}$ particles with a uniform distribution and a three-dimensional and dendritic structure on the surface of the films.

When these modified electrodes are introduced in $0.1 \mathrm{M} \mathrm{KCl}$ solution and cyclic voltametry was carried out, the polymer morphology changed. In all cases, unmodified PPy or PPy modified by copper or silver microparticles, the change is drastic, appearing holes on the polymer surface (the surface has holes and the cauliflower structures have been opened). Similar structure were recently presented in the literature about the behavior of PPy modified by carboxymethylcellulose in order to prevent the corrosion of steel [28].
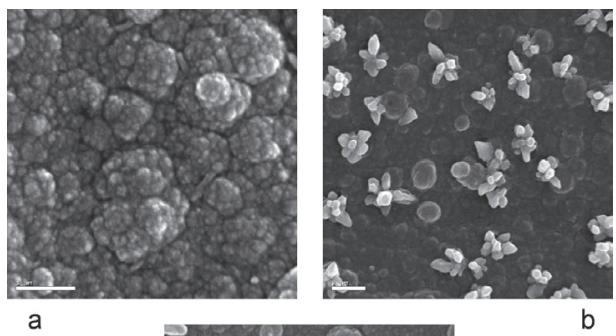

a

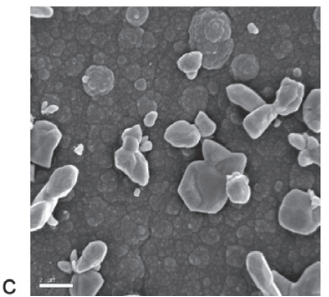

Figure 5: scanning electron microscopy of a) unmodified PPy film, b) PPy film modified with copper microparticles (PPy-Cu) and c) PPy film modified with silver microparticles (PPy-Ag).

\section{CONCLUSION}

In this work, a method providing effective deposition copper and silver microparticles onto electrogenerated polypyrrole films electrodes was demonstrated, by electroreduction of anionic copper and silver sulfate aqueous solution carried out through cyclic voltammetry and potentiostatic techniques. So, from the results presented here, we make the following conclusion: i) an first result indicate that the modification of conducting polypyrrole film by the deposition of copper and silver microparticles using electrochemical cementation can be achieved, ii) the voltammetric response of electrodes modified with metallic microparticles showed higher current and a shift in the peaks potentials compared to "unmodified" polymer electrode, iii) scanning electron microscopy studies indicate a three-dimensional and dendritic structure on the surface of the films showing a drastic change when the modified electrodes are cycled in $\mathrm{KCl}$, iv) modified PPy films by incorporation of copper and silver microparticles by using the cementation process exhibit the significant improvement of the conductivity and the stability of the PPy electrodes, v) The metallic microparticles were deposited in two from, elemental and valence ones. But, elemental copper and silver might be dissolved and less valence metal was left on PPy during anodic dissolution and therefore, the electrochemical experiment hinted that the (Cu)-PPy and (Ag)PPy interaction may involve a strong complex formation rather than a simple ion adsorption, vi) excluding the improvement in conductivity, the elemental metal demonstrates less influence on the characteristics of metal modified PPy. From the economic viewpoint, excess of elemental metal is unnecessary to modify the properties of PPy electrodes. 


\section{REFERENCES}

1. J. Sung, S. Kim, K. Lee, Fabrication of microcapacitors using conducting polymers microelectrodes, J. Power Sources 124 (2003) pp. 343.

2. A.A. Arrieta, M.L Rodríguez, V. Parra, A. Vegas, S. Villanueva, R. Gutiérrez, J.A. Saja, Fusion of Three Sensory Modalities for the Multimodal Characterization of Red Wines, IEEE Sens. J. 4 (2004) pp. 348.

3. Ö. Yavuz, M. Ram, M. Aldissi, P. Poddar, H. Srikanth, Polypyrrole composites for shielding applications, Synth. Met. 151 (2005) pp. 211.

4. A.A. Arrieta, C. Apetrei, M.L. Rodríguez-Méndez, J.A. de saja, Voltammetric sensor array based on conducting polymer-modified electrodes for the discrimination of liquids, Electrochim. Acta 49 (2004) pp. 4543.

5. M.A. Malik, M.T. Galkowski, H. Bala, B. Grzybowska, P.J. Kulesza, Evaluation of polyaniline films containing traces of dispersed platinum for protection of stainless steel against corrosion, Electrochim. Acta 44 (1999) pp. 2157.

6. B. J. Hwang, R. Santhanam, Y. L. Lin, Electrochemical deposition of gold metal particles into 3-dimensional polypyrrole film deposited on a highly oriented pyrolytic graphite, Electroanalysis 15 (2003) pp. 1667.

7. G. K. Chandler, D. Pletcher, The electrodeposition of metals onto polypyrrole films from aqueous solution, J. Appl. Electrochem. 16 (1986) pp. 62.

8. L. Torsi, M. Pezzuto, P. Siciliano, R. Rella, L. Sabbatini, L. Valli, Conducting polymers doped with metallic inclusions: New materials for gas sensors, Sens. Actuators B 48 (1998) pp. 362.

9. C. C. Chen, C. S. C. Bose, K. Rajeshwar, The reduction of dioxygen and the oxidation of hydrogen at polypyrrole film electrodes containing nanodispersed platinum particles, J. Electroanal. Chem. 350 (1993) pp. 161

10. D. J. Strike, N. F. De Rooij, M. Koudelka-Hep, M. Ulmann, J. Augustynski, Electrcatalytic oxidation of methanol on platinum microparticles in polypyrrole, J. Appl. Electrochem. 22 (1992) pp. 922.

11. K. Domansky, J. Li, J. Janata, Selective doping of chemically sensitive layers on a multisensing chip, J. Electrochem. Soc. 144 (1997) pp. 175.

12. L. Makhloufi, S. Bourouina, S. Hadad, Cementation de l'argent par le cuivre en milieu concentre de chlorures, Electrochim. Acta, 37 (1992) pp. 1179.

13. L. Makhloufi, B. Saidani, C. Cachet, R. Wiart, Cementation of $\mathrm{Ni}^{2+}$ ions from acidic sulfate solutions onto a rotating zinc disc, Electrochim. Acta, 43 (1998) pp. 3159.

14. L. H. Mendoza-Huizar, J. Robles and M. Palomar-Pardavé, Nucleation and growth of cobalt onto different substrates: Part I. Underpotential deposition onto a gold electrode, J. Electroanal. Chem. 521 (2002) pp. 95.
15. H. Hammache, L. Makhloufi, B. Saidani, Corrosion protection of iron by polypyrrole modified by copper using the cementation process, Corros. Sci. 45 (2003) pp. 2031

16. R. J. Nichols, E. Bunge, H. Meyer, H. Baumgärtel, Classification of growth behaviors for copper on various substrates with in-situ scanning probe microscopy, Surf. Sci., 335 (1995) pp. 110.

17. C. S. C. Bose, K. Rajeshwar, Efficient electrocatalyst assemblies for proton and oxygen reduction: the electrosynthesis and characterization of polypyrrole films containing nanodispersed platinum particles, J. Electroanal. Chem. 333 (1992) pp. 235.

18. L. M. Abrantes, J. P. Correia, Polypyrrole incorporating electroless nickel, Electrochim. Acta 45 (2000) pp. 4179.

19. C. de la Fuente, J. A. Acuña, M. D. Vázquez, M. L. Tascón, M. I. Gómez, P. Sánchez Batanero, Preparation of a polypyrrole electrode modified with a nickel phthalocyanine complex. Application to the determination of an antioxidant (propylgallate) in foods, Talanta 44 (1997) pp. 685.

20. A. Zouaoui, O. Stéphan, M. Carrier, J-C. Moutet, Electrodeposition of cooper into functionalized polypyrrole films, J. Electroanal. Chem. 474 (1999) pp. 113.

21. R. J. Nichols, D. Schröer, H. Meyer, An in situ scanning probe microscopy study of copper electrodeposition on conductive polypyrrole, Electrochim. Acta, 40 (1995) pp. 1479.

22. G. Tourillon and D. GuayA. Tadjeddine, In-plane structural and electronic characteristics of underpotentially deposited copper on gold (100) probed by in-situ X-ray absorption spectroscopy, J. Electroanal. Chem., 289 (1990) pp. 263.

23. R. Zamboni, C. Taliani, P. Dannetun, M. Boman, S. Stafström, W. R. Salaneck, R. Lazzaroni, C. Fredriksson, J. L. Brédas The chemical and electronic structure of the interface between aluminum and polythiophene semiconductors, J. Chem. Phys. 99, (1993) pp. 664.

24. Y.J. Yuan, S.B. Adeloju, G.G. Wallace, In-situ electrochemical studies on the redox properties of polypyrrole in aqueous solution, Eur. Polym. J. 35 (1999) pp. 1761.

25. G. Appel, O. Böhme, R. Mikalo and D. Schmeißer, The polaron and bipolaron contributions to the electronic structure of polypyrrole films, Chem. Phys. Lett. 313 (1999) pp. 411.

26. S. Brazovskii, N. Kirova, A. R. Bishop, Z. G. Yu and A. Saxena, Stability of bipolarons in conjugated polymers, Opt. Mater. 9 (1998) pp. 502.

27. S-H. Song, K-M. Park, W-S. Kim, S-M. Chang, Analysis of the characteristics of electrochemically polymerized polypyrrole films by using QCA and AFM, Mater. Sci. Eng. C 24 (2004) pp. 225.

28. P. Herrasti, P. Ocon, Polypyrrole lavers for steel protection, Appl. Surf. Sci. 172, (2001), pp. 276. 